\title{
Comparing Social Support in Adolescents Interested in Different Types of Computer Games
}

Muhammad-Ali Fardin

$\mathrm{PhD}$ Candidate in Educational Psychology, Dept. of Psychology, Faculty of Psychology, Islamic Azad University, Zahedan Branch (IAUZAH), Zahedan, Iran

Mahmoud Shirazi

*Assistant Professor, Dept. of Psychology, Faculty of Education and Psychology, University of Sistan and Baluchestan (USB), Zahedan, Iran (Corresponding author)mshirazi@edpsy.usb.ac.ir

Received: 16 February 2016 Accepted: 02 JuNe 2016

\section{ABSTRACT}

Background and objective: With the advancement of networks and the Internet industry, computer games have considerably progressed in the recent years and have been released in various types. Hence, the objective of this study was to compare social support in adolescents interested in different types of computer games.

Materials and methods: This descriptive study followed a casual-comparative design. The statistical population of this study included all male adolescents and young adults referred to Internet gaming centers in Zahedan, Iran. In this study, multi-stage cluster sampling method was applied through which 8 gaming centers were randomly chosen and then among all people who referred to the considered gaming centers, 156 individuals were selected randomly as the regarded sample. To gather the data, the Mary Procidano and Kenneth Heller's Social Support Questionnaire (1983) was applied. To analyze the data, frequency, percentage, medium, mode and SD and one- way ANOVA and post hoc Scheffe's test was used through SPSS 23.

Results: There was a difference among social support of people interested in different types of computer games. In this regard, those who were interested in online multiplayer games perceived higher levels of social support compared to those who were interested in single player games $(p \leq 0.05)$. Moreover, the findings demonstrated that subjects who chose Internet gaming centers and their houses as places to play compared to those who only selected their houses to play had higher levels of perceived social support.

Conclusion: With the increasing development of computer games and diversification and expansion of its different styles, each type of computer games should be studied and investigated distinctly.

Paper Type: Research Article.

Keywords: Social Support, Adolescents, Types of Computer Games, Internet Gaming Centers, Zahedan.

Citation: Fardin M.A., Shirazi M. Comparing Social Support in Adolescents Interested in Different Types of Computer Games. Iran J Health Educ Health Promot. Spring 2016;4(1): 65-73. 


\section{جكيده}

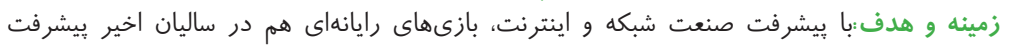

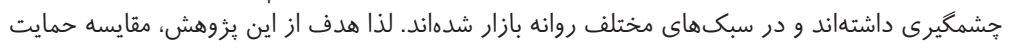

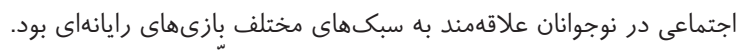

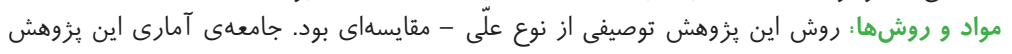

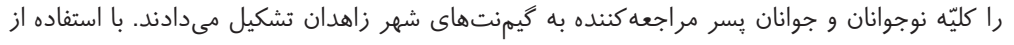

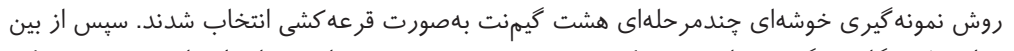

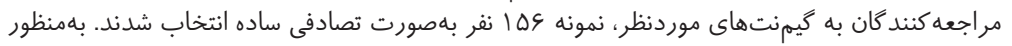

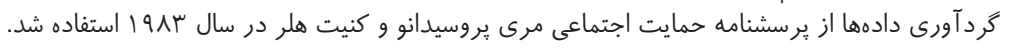

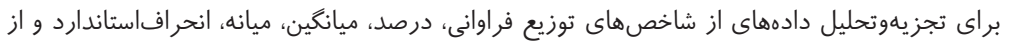

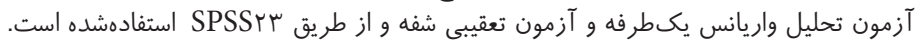

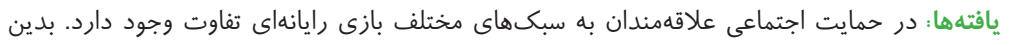

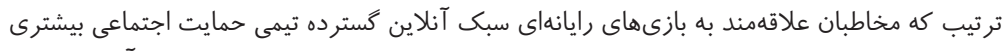

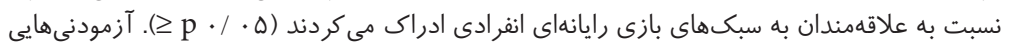

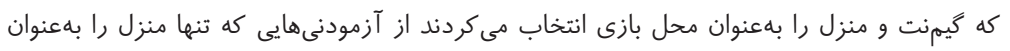

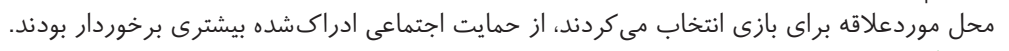

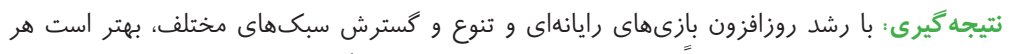

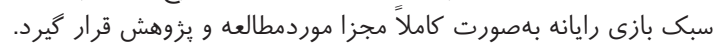
نوع مقاله : مطالعه يز بزوهشى. كليدوازه: حمايت اجتماعى، نوجوانان، سبك بازى رايانهاى، گيمنت، زاهدان.

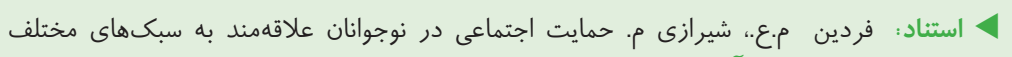

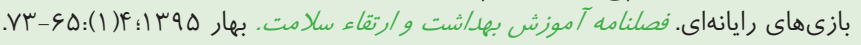

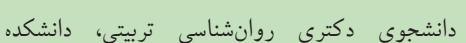

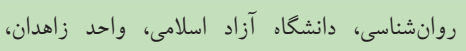
زاهدان، ايران محمود شير ازى اندان

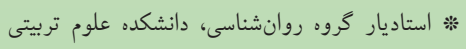

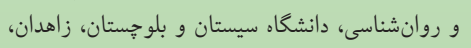

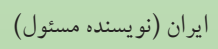
mshirazi@edpsy.usb.ac.ir

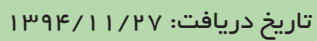

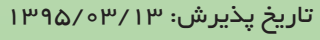


بيش از جند دهه است كه بازىهاى رايانهاى، در بين اقشار اجتماعى (4).

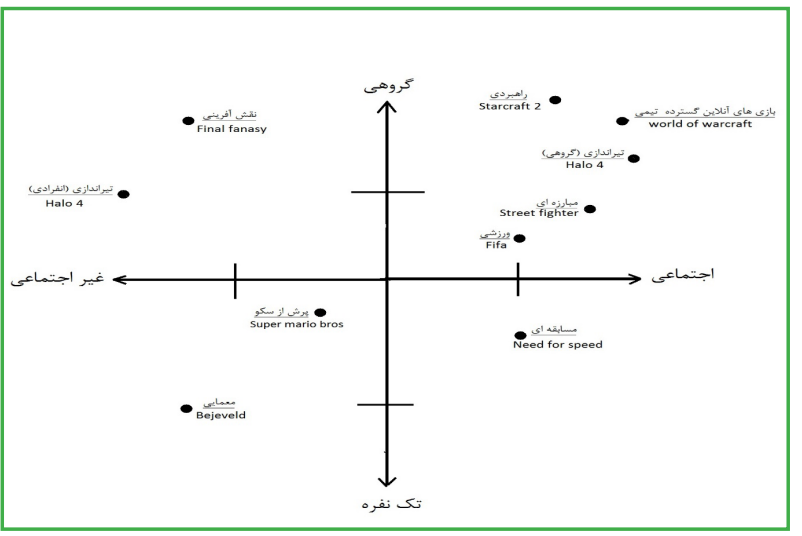

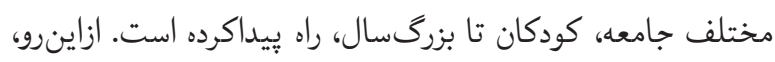

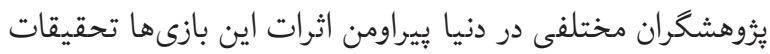
مختلفى انجام دادهاند؛ اما اكثر يُزوهشها در اين زمينه نتوانسته

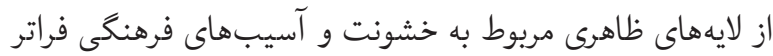

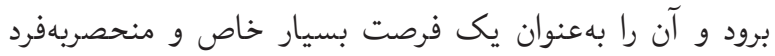
بهمنظور انتقال مفاهيم و حمايتهاى اجتماعى ادراكشده در بهرئر

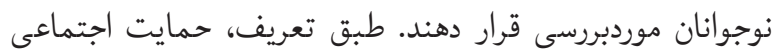
به ادراك يا تجربه يك فرد از اينكه او را دوست دارند، به او توجه

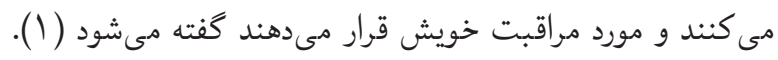
شكل ا. نقشه مفهومى از زانرهاى اصلى بازىهاى ويدئوئى بر حسب

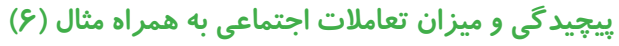

با توجه به شكل ا و تنوع روزافزون بازىهاى رايانهاى، اين

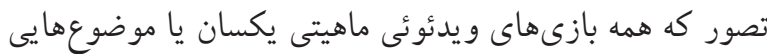

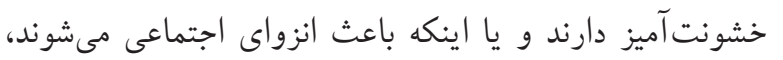

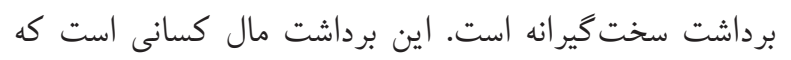

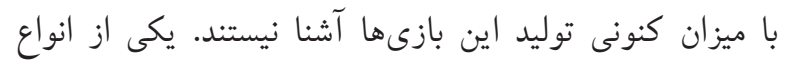

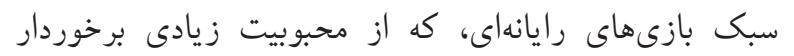

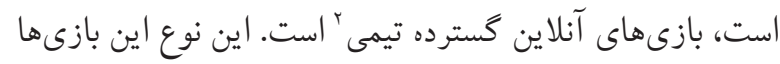

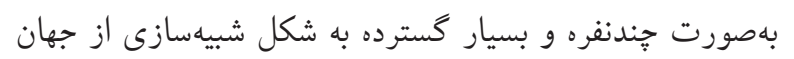
واقعى و سهبعدى طراحى شده است كه در آن افراد به همكارى تسيل

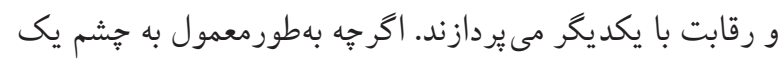

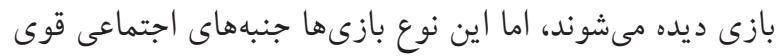

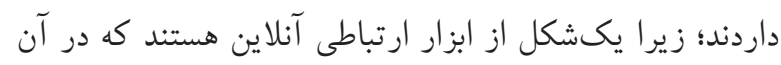

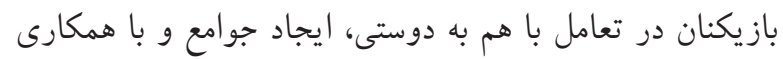

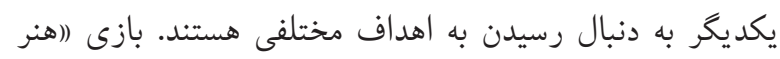

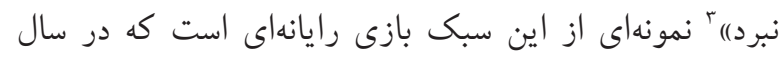

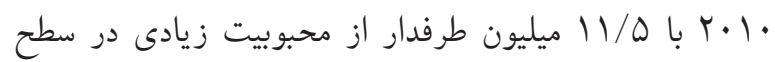

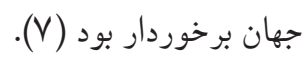

2. Massively multiplayer online game

3. World of Warcraft

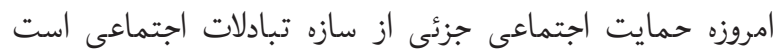

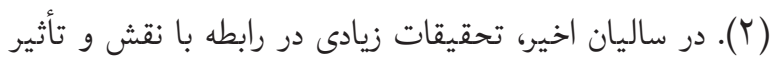

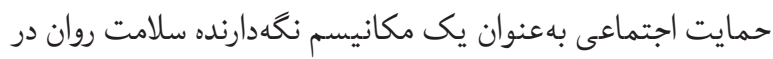

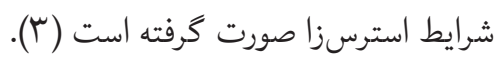

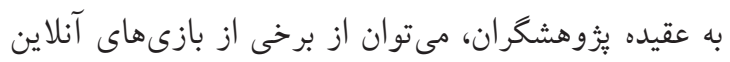

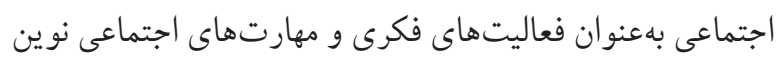

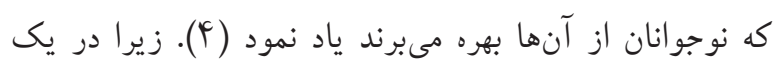
دهه كذشته، بازىهاى آنلاين و اجتماعى، محبوبيت گستردهاى

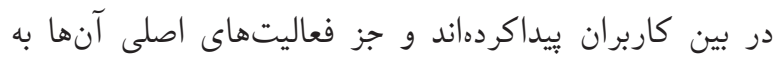

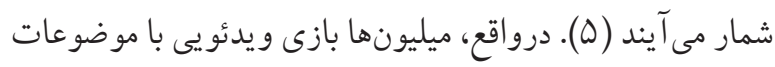

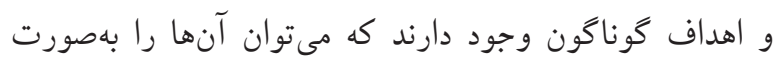

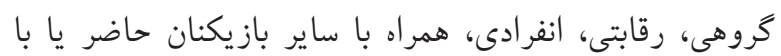

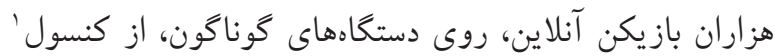

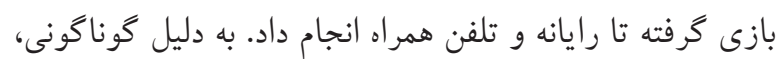
ازلحاظ زانر و ابعاد كوناگونى كه بازىهاى ويدئويى مى توانند داشته باشند، تدوين يك طبعهبندى از بازى هاى رايانهاى معاصر، روزبهروز دشوارتر مىشود. البته متخصصان زيادى سعى كرداند اين كار را انجام دهند. باينحال، براى اينكه نكاهى به اين اين

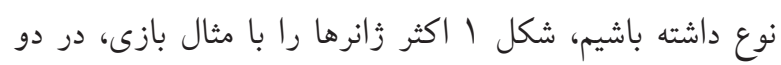


علاوه بر اين، نتايج نشان دادهاند كه عوامل مختلفى ازجمله نحوه

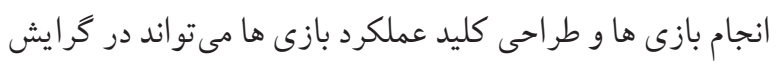

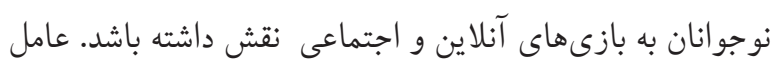

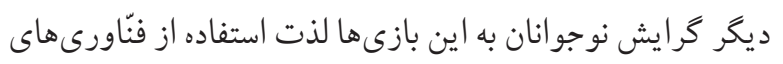

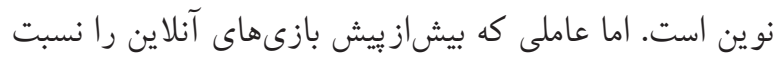

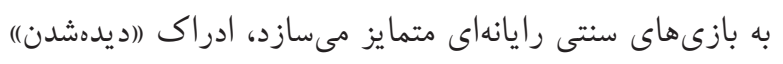
است؛ زيرا از طريق كسب امتيازات بيشتر در بازى و به اشتراى

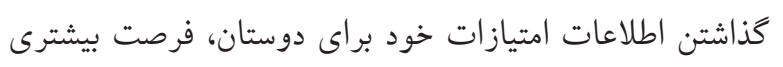

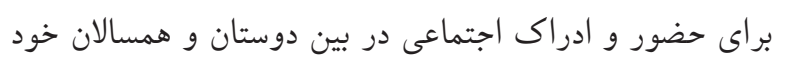

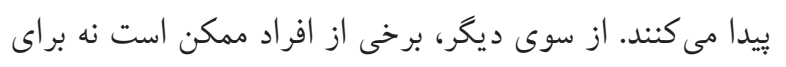

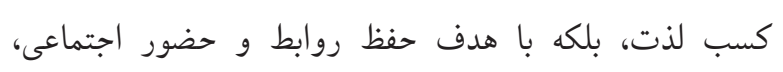

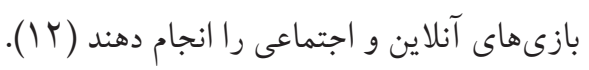

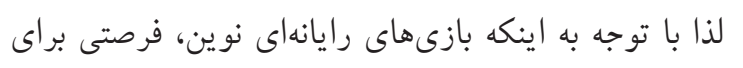

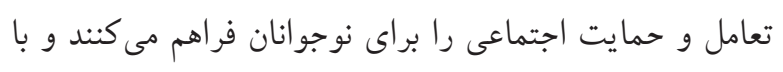

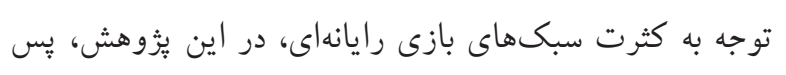

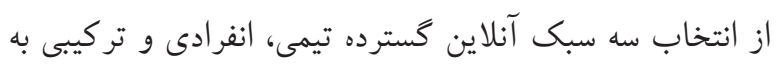

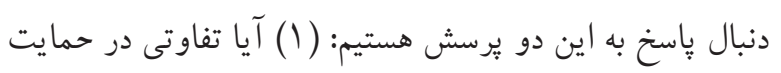

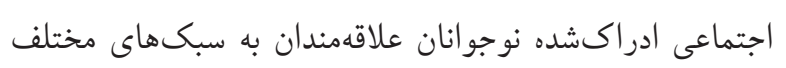
بازى رايانه وجود دارد؟ و (Y) آيا تفاوتى در حمايت اجتماعى أنى ادراكشده نوجوانان علاقهمند بازىهاى رايانهاى با تأكيد بر محل

$$
\text { بازى وجود دارد؟ }
$$

مو اد و روش ها روش اين يُزوهش توصيفى، از نوع علّى ـ مقايسهاى بود. جامعه

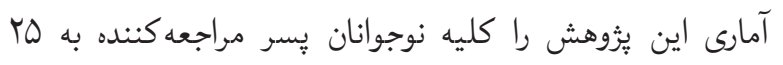

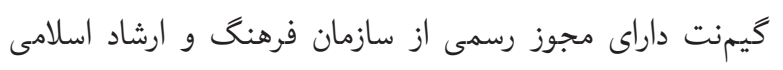

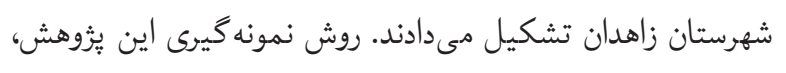

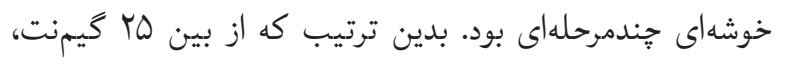
هشت كيمنت بهصورت قرعه كشى انتخاب شدند. ازآنجايى كه

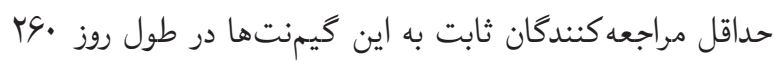

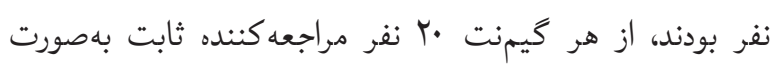

برخى از يُزوهشكران از بازىهاى آنلاين گسترده تيمى

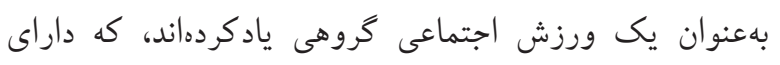

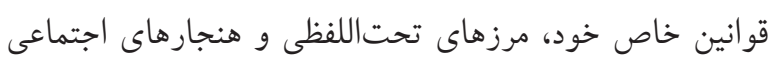

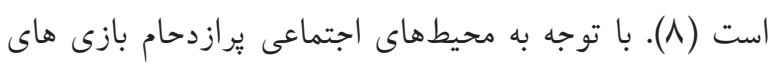

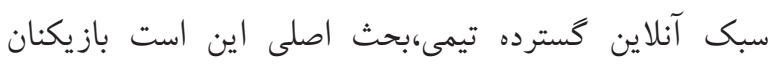

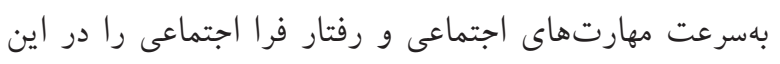

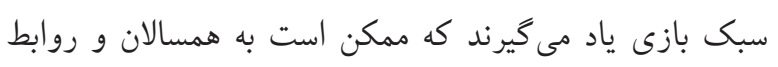

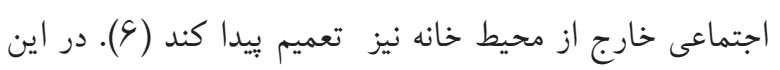

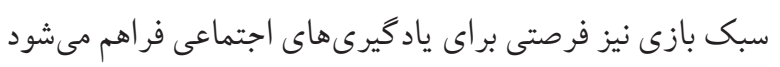

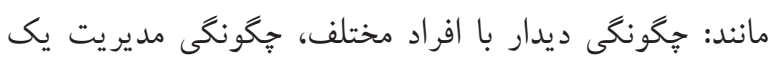

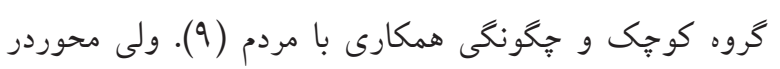

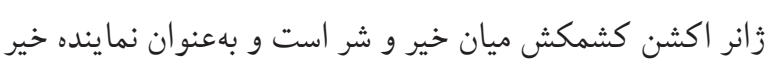

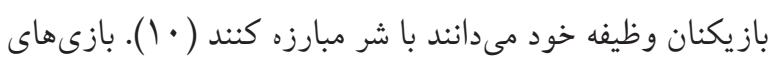

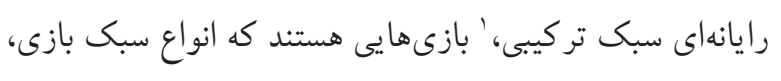

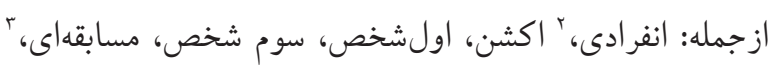

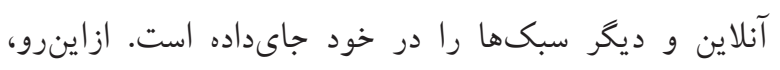
همانطور كه اساتيد اين رشته اذعان كردهاند برشمردن (رأثيرات

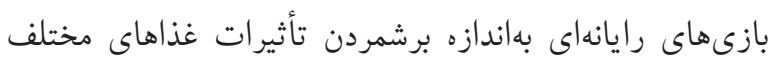
سخت است) (9). بنابراين، بهجاى اينكه بازىهاى ويدئويى و اثرات لـ آن آن را

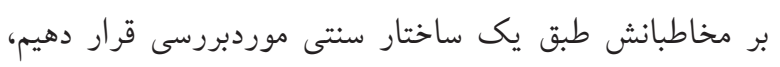

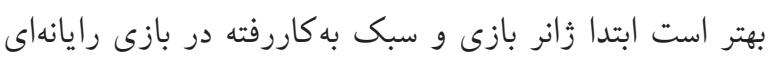
موردنظر را ازلحاظ انفرادى، گروهى يا رقابتى بودن معين كنيم.

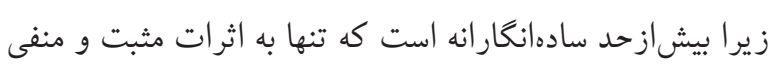
تمامى بازىهاى رايانه بيردازيم و به ابعاد مختلف اين بازى هاريا

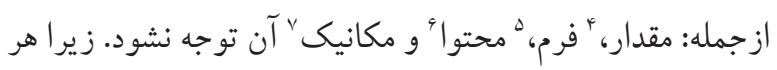

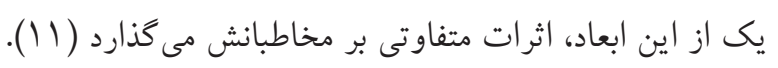


بافتنه آمارههاى توصيفى مخاطبان بازى هاى رايانهاى بر اساس جنسيت، سن، ساعات انجام بازى در طول روز، محل موردعلاقه براى انجام

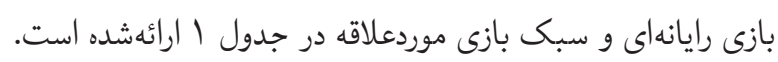

جدول ا. فراوانى و فراوانى نسبى مراجعه كنند گان به گيمنتهاى

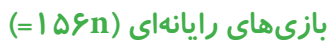

\begin{tabular}{|c|c|c|c|}
\hline$\%$ & فراوانى & & \\
\hline $1 \ldots$ & $1 \Delta G$ & مرد & جنسيت \\
\hline$V / \mathrm{I}$ & 11 & $1 \cdot-V$ & \multirow{5}{*}{ سن (سال) } \\
\hline$F \Delta / 0$ & VI & $10-11$ & \\
\hline$r I / \Lambda$ & mp & $r \cdot-19$ & \\
\hline $18 / 9$ & rᄉ & $r \Delta-r l$ & \\
\hline$V / V$ & Ir & $r \cdot-r q$ & \\
\hline $1 V / 9$ & rᄉ & كمتر از يك & \multirow{5}{*}{$\begin{array}{c}\text { سابقه انجام بازى } 1 \text { (سانهاى) } \\
\text { (سال) }\end{array}$} \\
\hline$\Lambda / r$ & Ir & $r-1$ & \\
\hline r & rv & $f-r$ & \\
\hline $1 / \mu$ & r & $\checkmark-\Delta$ & \\
\hline $\mathcal{F} \wedge / \mathrm{V}$ & VG & $+\Lambda$ & \\
\hline$r s / 9$ & Fr & $1-\cdot / 0$ & \multirow{5}{*}{ ميزان ساعات در طول روز } \\
\hline $1 N / 9$ & $r q$ & $r-1$ & \\
\hline$r / s$ & r & $r-r$ & \\
\hline$r / r$ & $\Delta$ & $\Delta-r$ & \\
\hline $\mathcal{F} \wedge / \mathrm{V}$ & VS & $+\Delta$ & \\
\hline$r Y / F$ & ro & منزل & \\
\hline$r \cdot / \Lambda$ & $\uparrow \wedge$ & كيمنت & محل موردعلاقه براى انجاز رايانهاى \\
\hline 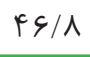 & $v^{m}$ & منزل و گيمنت & \\
\hline$r q / 1$ & 41 & كسترده آنلاين & \\
\hline$r V / r$ & $\Delta \lambda$ & بازىهاى انفرادى & سورد سلاقه بازى \\
\hline$r \mu / V$ & rV & تر كيبى & \\
\hline
\end{tabular}

تصادفى ساده (قرعه كشى) از بين اسامى موجود در كيمنت انتخاب شدند و برسشنامه در بين آنها توزيع كرديد. درنهايت،

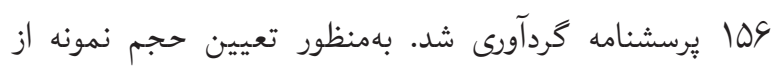
فرمول كوكران استفاده شد. ابزار كردآورى دادهها (برسشنامه حمايت اجتماعى (مقياس دوستان)') بود. اين ثرسشنامه توسط مرى يروسيدانو و كنيت

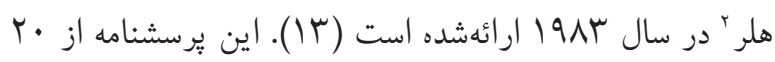

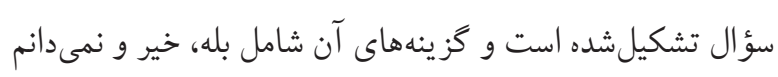

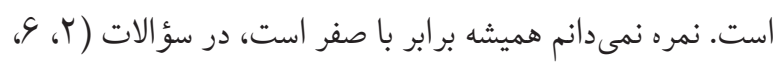

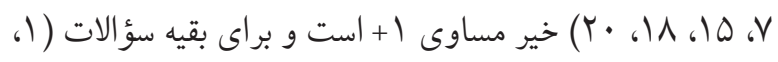

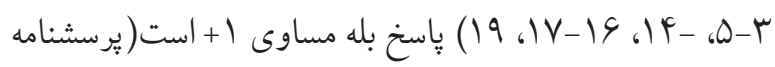

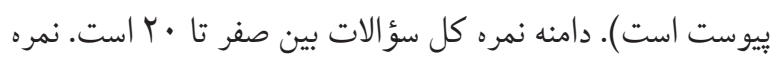

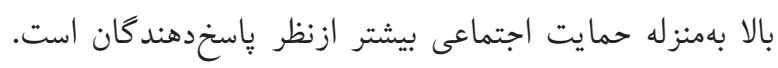

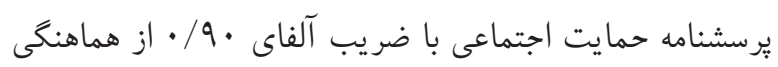

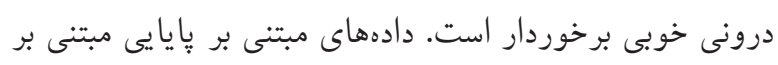
• ب سؤال اصلى مقياسها قبل از تفكيك حمايت خانو اده است.

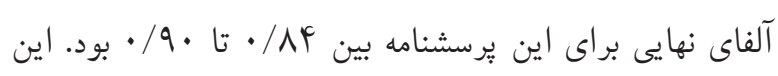

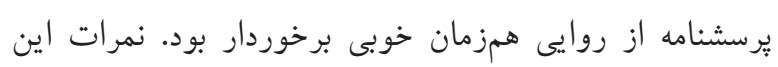

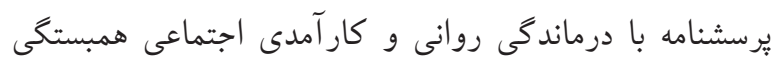

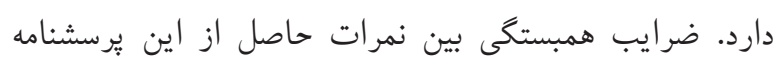

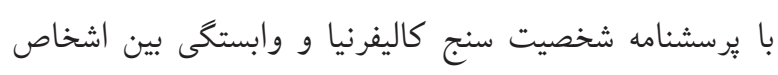

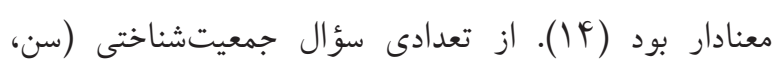
سابقه انجام بازى، ميزان ساعات انجام بازى در طول روز، محل

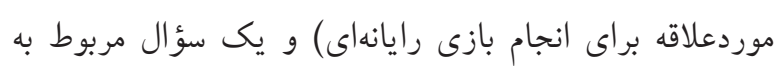
سبك بازى موردعلاقه مخاطبان از بين سه كزينه (1-آنلاين

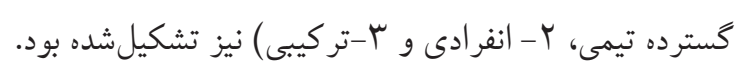

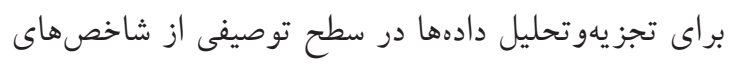

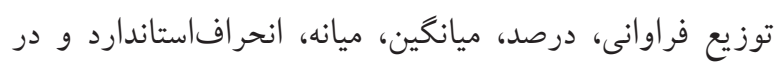
سطح استنباطى از آزمون تحليل واريانس يكطرفه (ANOVA)

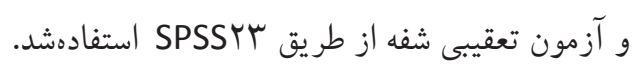

1. Perceived Social Support from Friends (PSSFR)

2. M. E. Procidano \& K. Heller 
سبك انفرادى تفاوت معنادارى وجود داشت (ه • / • p p)؛ اما

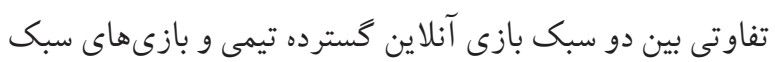

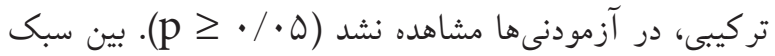

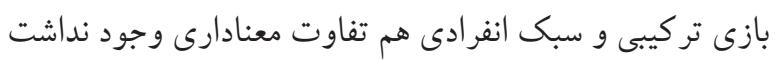

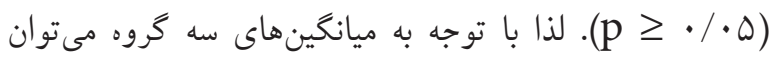
دريافت كه به ترتيب بازيكنان سبكهاى بازى آنلاين گسترده تيمى و سبك تركيبى بيشترين حمايت اجتماعى را نسبت به سبك بازى انفر ادى ادراك مى كنند.

جدول אا. نتايج آزمون تحليل واريانس يكطرفه، بهمنظور مقايسهى

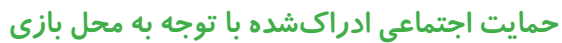

\begin{tabular}{|c|c|c|c|c|c|c|}
\hline معنادارى سطح & F & ميانكين & df & مجذورات & & متغير \\
\hline$\cdot / \cdot$ & $1 . / .9 V$ & rSV/\&AI & $r$ & DTD/rGY & بين گروهها & \multirow{2}{*}{ اجتماعى } \\
\hline & & $r s / 0 q$. & $10 r$ & $F \cdot G \Lambda / T F V$ & درون گروهها & \\
\hline & & & 100 & $f G \cdot r / s \cdot q$ & جمع & \\
\hline
\end{tabular}

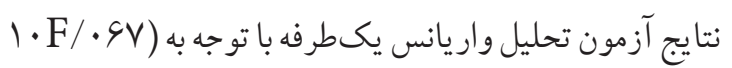

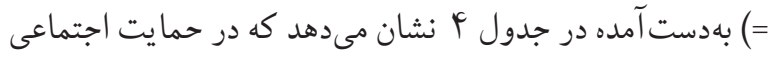

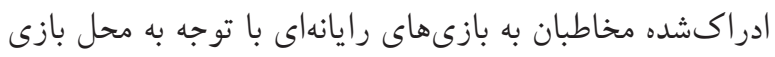

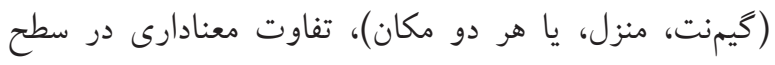

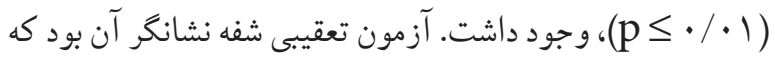
ازلحاظ حمايت اجتماعى ادراكشده با توجه به محل بازى تفاوت

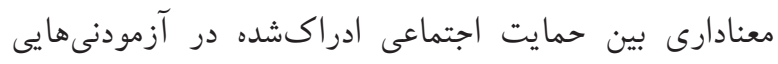

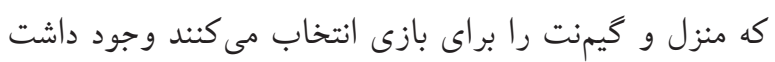

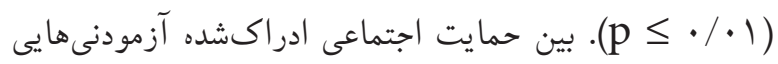

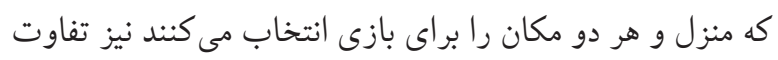

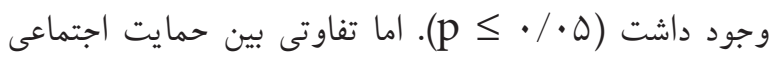

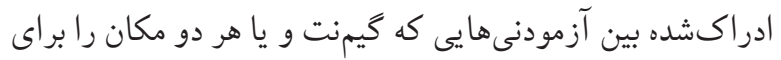

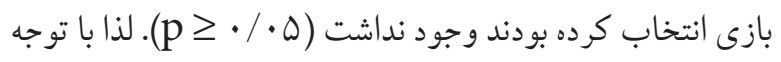

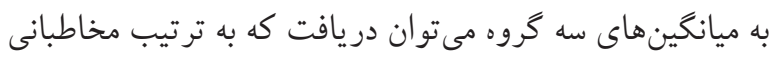
كه گيمنت و هر دو مكان (كيمنت و منزل) را براى بازى انتخاب

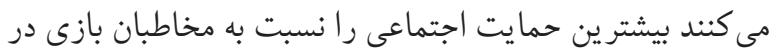

جدول r. شاخصهاى گرايش مر كزى گروههاى نمونه بر اساس سبك بازى موردعلاقه و محل بازى موردعلاقه مرك

\begin{tabular}{|c|c|c|c|c|}
\hline انحراف & ميانغين & فراوانى & سبك و محل موردعلاقه & متغير \\
\hline$\Delta / \Delta q$ & $\mid f / \cdot f$ & 91 & آنلاين گسترده تيمى & \multirow{3}{*}{ حمايت اجتماعى } \\
\hline$\Delta / F G$ & $11 / 10$ & $\Delta \Lambda$ & انفر ادى & \\
\hline$F / \Delta \varphi$ & $I T / \Delta F$ & rv & بازىهاى تر كيبى & \\
\hline $8 / \cdot 1$ & $9 / F \Delta$ & ro & منزل & \multirow{3}{*}{ حمايت اجتماعى } \\
\hline$\Delta / 1$. & $I F / Y V$ & iᄉ & يمنت & \\
\hline$F / \& \Lambda$ & $\mid r / \Delta F$ & $V^{\mu}$ & هر دو مكان & \\
\hline
\end{tabular}

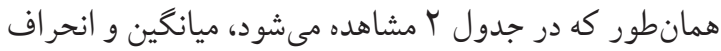

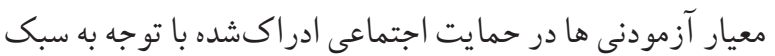

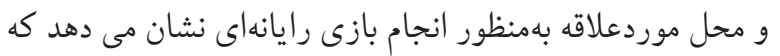

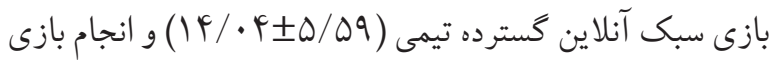
در منزل و كيم نت (S/ حمايت اجتماعى ادراك شده مى باشند. جدول س. نتايج آزمون تحليل واريانس يكىطرفه، بهمنظور مقايسهى

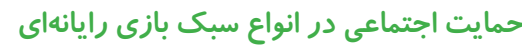

\begin{tabular}{|c|c|c|c|c|c|c|}
\hline معنادارى سطح & $\mathbf{F}$ & ميانغين & df & مجذورات & & متغير \\
\hline \multirow[t]{3}{*}{.$/ \cdot 9$} & $r / \lambda \cdot r$ & $\mid r \Delta / q \wedge r$ & $r$ & rVI/GGF & بين گروهها & \multirow{2}{*}{ جتماعيت } \\
\hline & & rN/TII & lor & 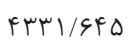 & درون گروهها & \\
\hline & & & 100 & \&G. r/G. q & جمع & \\
\hline
\end{tabular}

همانطور كه در جدول ب مشاهده مىشود، نتايج آزمون

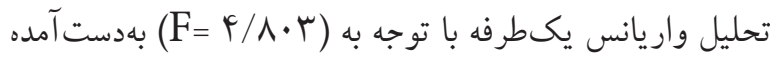
نشان مىدهد كه در حمايت اجتماعى گروههاى مختلف علاقهمند

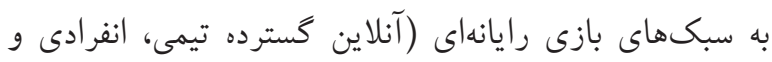
تركيبى)، تفاوت معنادارى در سطح (ه • (

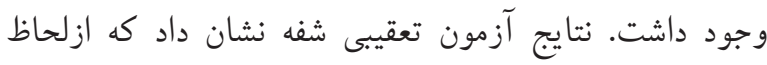
حمايت اجتماعى در بين مخاطبان سبك آنلاين گسترده تيمى با بان 
ييشين، يعنى جنتايل و همكاران (IV) و كول و همكاران (IN)

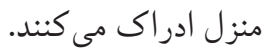
همسو بود.

نتايج بُزوهش تير و نيلسون' نشان داد كه حتى خشنترين

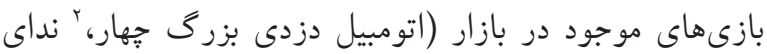

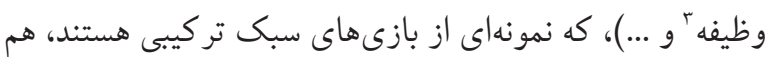

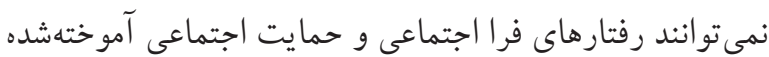

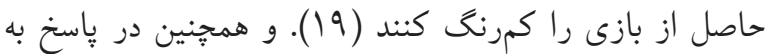

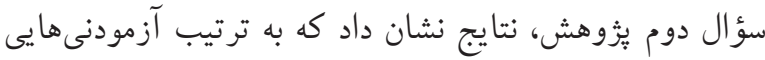

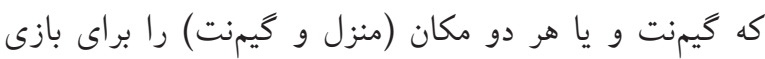

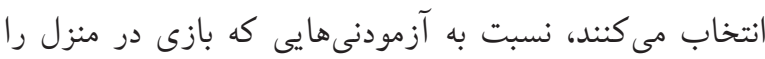
انتخاب كردهاند، حمايت اجتماعى بيشترى را ادراك مى كنند.

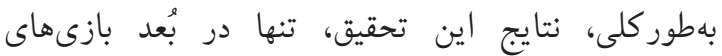

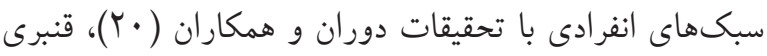

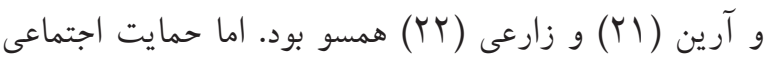
ادراكشده، در علاقهمندان به بازىهاى رايانهاى سبك آنلاين كسترده تيمى يا سبكهاى تركيبى بيشتر از سبك انفرادى بود.

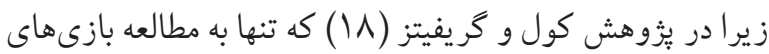

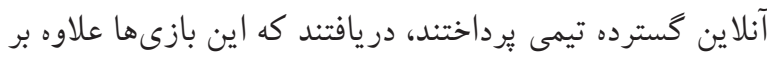

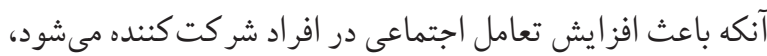
خود نيز زمينهساز دوست يابى و روابط عاطفى محكم مى شود. اين تحقيق نشان داد كه بازى آنلاين گسترده تيمى مى تواند درزمينه

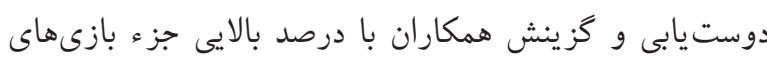

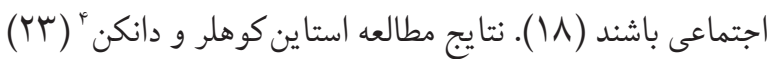

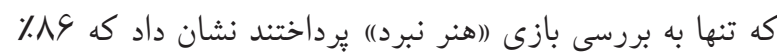

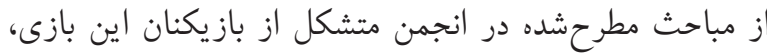
مباحثى است كه ساخت دانش اجتماعى ه را به دنبال دارد. نتيجاه گيرى مباحئ اسن نتايج اين يزوهش نشان داد كه علاقهندان به بازىهاى سبك

1. Tear \& Nielsen

2. Grand Theft Auto IV

3. Call of Duty

4. Steinkuehler \& Duncan

5. social knowledge construction

بازىهاى ويديويى، بهويثه بازىهاى آنلاين اجتماعى، از محبوبيت

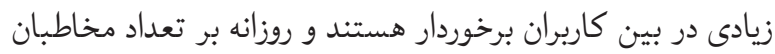

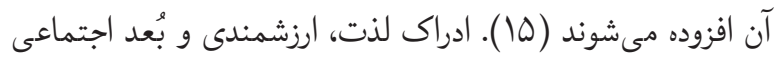
ازجمله عوامل گرايش نوجوانان به بازىهاى آنلاين امروزى است.

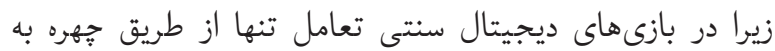

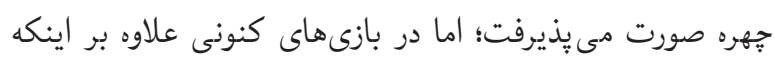
اين بازىها هيج گونه محدوديت زمانى و مكانى ندارند، شرايطى صنى

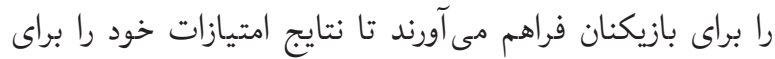

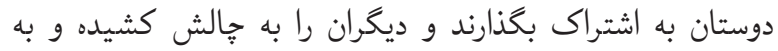
رقابت دعوت نمايند. ديده شدن از طريق امتيازات بهدست آمده

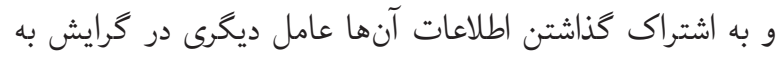
انجام اين سبك از بازىها هستند كه خود نمونهاى از حمايت

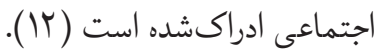
با توجه به رشد و نفوذ اينترنت، بازىهاى اجتماعى و آنلاين

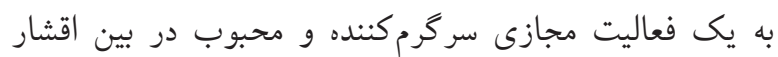
مختلف جامعه ازجمله نوجوانان تبديلشدهاند (4) (1). ساعات زيادى از وقت نوجوانان در منزل و در گيمنتها به بازى صرف

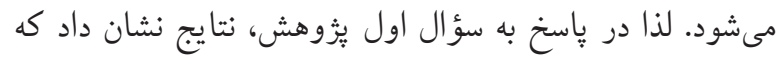
مخاطبان بازىهاى سبك آنلاين گسترده تيمى داراى بيشترين

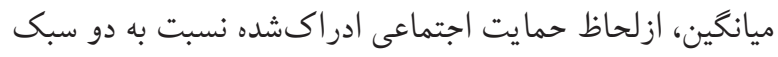
انفر ادى و تر كيبى بودند. به نظر مىرسد بازيكنان مهارتهاى مهم

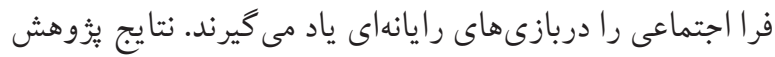

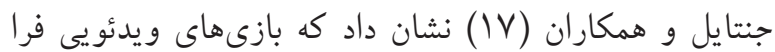
اجتماعى، علاوه بر اينكه با رفتارهاى فرا اجتماعى رابطه داشته،

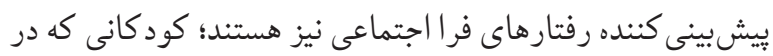
ابتداى سال تحصيلى بازىهايى با سبك فرا اجتماعى ترى را بازى كنند، بهاحتمالزياد در اواخر سال رفتارهاى يارىرسانى بيشترى از خود نشان مىدهند (IV). نتايج اين يُزوهش با تحقيقات 
در رابطه با آن يرداخته شود. زيرا با توجه به نتايج يثوهشهايى كه به مطالعه موردى برخى از سبكهاى بازى يرداختند و همجنِين نتايج يثوهش حاضر، مىتوان بيان داشت تا بازىهاى رايانهاى را بهطور كاملاً تخصصى نشناسيم، بههيجوجه نمى توان موضع گيرى خاصى نسبت به آن داشت.

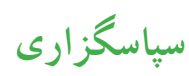

نويسند گان مقاله بر خود لازم مى دارند از مسئولين دانشخاه

آزاد اسلامى واحد زاهدان، سازمان فرهنگ و ارشاد اسلامى استان

سيستان و بلوجستان و كليه كيمنتهايى كه در انجام اين يثزوهش ما را يارى نمودند كمال تقدير و تشكر را داشته باشند.

\section{References}

1. Taylor S.E. Sherman K.k. kim H.S. Jarcho. J. Ta kagi K. dunagan S. Culture and social support: who seeks it and why?. Journal of personality and social psychology 2004; 87(3): 354-362.

2. Chan k.w. Wyatt T.A. Quality of life: A study of employee in shanghai, china. Asia pacific Business Rev 2007;13(4): 501-517.

3. Tonsing K. Zimet G.D. Tse S. Assessing social support among South Asians: The multidimensional scale of perceived social support. Asian Journal of Psychiatry 2012; 5: 164-168.

4. Seo S. DaCosta B. Predicting Video Game Behavior: An Investigation of the Relationship Between Personality and Mobile Game Play. Games and Culture 2015; 10(5): 481501.

5. VafaiNajar A, Masihabadi M, Moshki M, Ebrahimipour $H$, Tehrani $\mathrm{H}$, Esmaeli $\mathrm{H}$, et al. Determining the Theory of Planned Behavior's Predictive Power on Adolescents' Dependence on Computer Games. Iranian Journal of Health Education and Health Promotion. 2015;2(4):30311.

6. Granic s. Lobel A. Rutger c. Engels M. The Benefits of Playing Video Games. American Psychological Association 2014; 69:66-78.

7. Barnett J. Coulson M. Virtually Real: A Psychological Perspective on Massively Multiplayer Online Games. Review of General Psychology 2010; 14: 167-179.

8. Williams D. Ducheneaut N. Xiong L. Zhang Y. From tree house to barracks: The social life of guilds in World of Warcraft. Games \& Culture 2006;1: 338-361.

9. Ducheneaut N. Moore R.J. More than just XP learning social skills in massively multiplayer online games. Interactive
آنلاين، حمايت اجتماعى بيشترى را ادراك مى كنند. زيرا بهواسطه انجام بازىهاى آنلاين، بدون هيج گونه حدومرزى به صحبت و انجام بازى با همسالان خود مى يردازند؛ كه اين حمايت و اين ادراك اجتماءى در دو سبك بازى ديخر مشاهده نشد. درواقع، اين گونه مىتوان نتيجه كرفت كه برخى از سبكهاى بازىهاى رايانهاى، ازجمله آنلاين كسترده تيمى، نهتها باعث انزوا و گوشه گيرى نمىشوند، بلكه زمينه ساز برقرارى روابط اجتماعى با ساير مخاطبان اين بازىها مىشوند. ازاينرو، نتايج تحقيق حاضر مى تواند دانش موجود در اين زمينه را گامى به يِيش ببرد. لذا بهتر است ابتدا بازىهاى رايانهاى را بهطور دقيق و با توجه به سبك

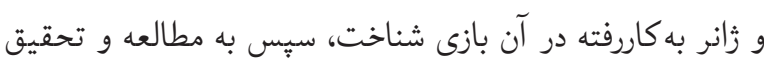

Technology \& Smart Education 2005; 2: 89-100.

10. Jalalzadeh B. Duran B. Decoding computer games: A Case Study conducted on "Special Operation 85". Cultural Research Journal 2009; 2: 77-96. [Persian]

11. Gentile D. A. Stone W. Violent video game effects on children and adolescents. A review of the literature Minerva Pediatr 2005; 57: 337-358.

12. Sn Y. Zhao Y. Qi Jia Sh. Yi Zheng D. Understanding the Antecedents of Mobile Game Addiction: The Roles of Perceived Visibility Perceived Enjoyment and Flow 2015; PACIS 2015 Proceeding: Paper 141

13. Procidano M. E. Heller K. Measures of perceived social support from friends and from family: Three validation studies, American Journal of Community Psychology 1983; 11: 1-24.

14. Sanaei B. Measures of marriage and family. Tehran: Be'sat Publicaion 2008. [Persian]

15. Simões J.Redondo R.D. Fernández Vilas A. A social gamification framework for a K-6 learning platform. Computers in Human Behavior 2013; 29(2):345-353.

16. Erturkoglu Z. Zhang J. Mao E. Pressing the Play Button: What Drives the Intention to Play Social Mobile Games?. International Journal of E-Business Research 2015; 11(3).

17. Gentile D A. Anderson C A. Yukawa S. The effects of prosocial video games on prosocial behaviors: International evidence from correlational, longitudinal and experimental studies. Personality and Social Psychology Bulletin 2009; 35: 752-763.

18. Coole H. Griffiths M. Social Interactions in massively multiplayer online role-playing gamers. Cyber psychology \& behaviour 2007; 4 .

19. Tear M.J. Nielsen M. Failure to demonstrate that playing violent video games diminishes prosocial behavior. PLOS 
2013; 8: Issue 7.

20. Duran B. Azadfallah P. Ejei J. Examining computer games and social skills of adolescents. Journal of Psychology 2002; 21[in Persian].

21. Ghanbari F. Arian K.h. Investigating the relationship of computer games with electronic friendship and social isolation of elementary school students in Tehran.M.A Thesis of educational sciences, elementary education. Tehran: Allameh Tabataba'i University, Faculty of
Psychology and Educational Sciences 2007. [Persian]

22. Zarei A. Examining the relationship between computer games and social skills of male high school students in Persians. M.A. Thesis in Educational Psychology. Tehran: University, Faculty of Psychology and Educational Sciences 2008. [Persian]

23. Steinkuehler S. Duncan S. Scientific Habits of Mind in Virtual Worlds. Journal of Science Education and Technology 2008; 17: 530-543.

״رسشامه حمايت اجتماعى (مقياس دوستان)

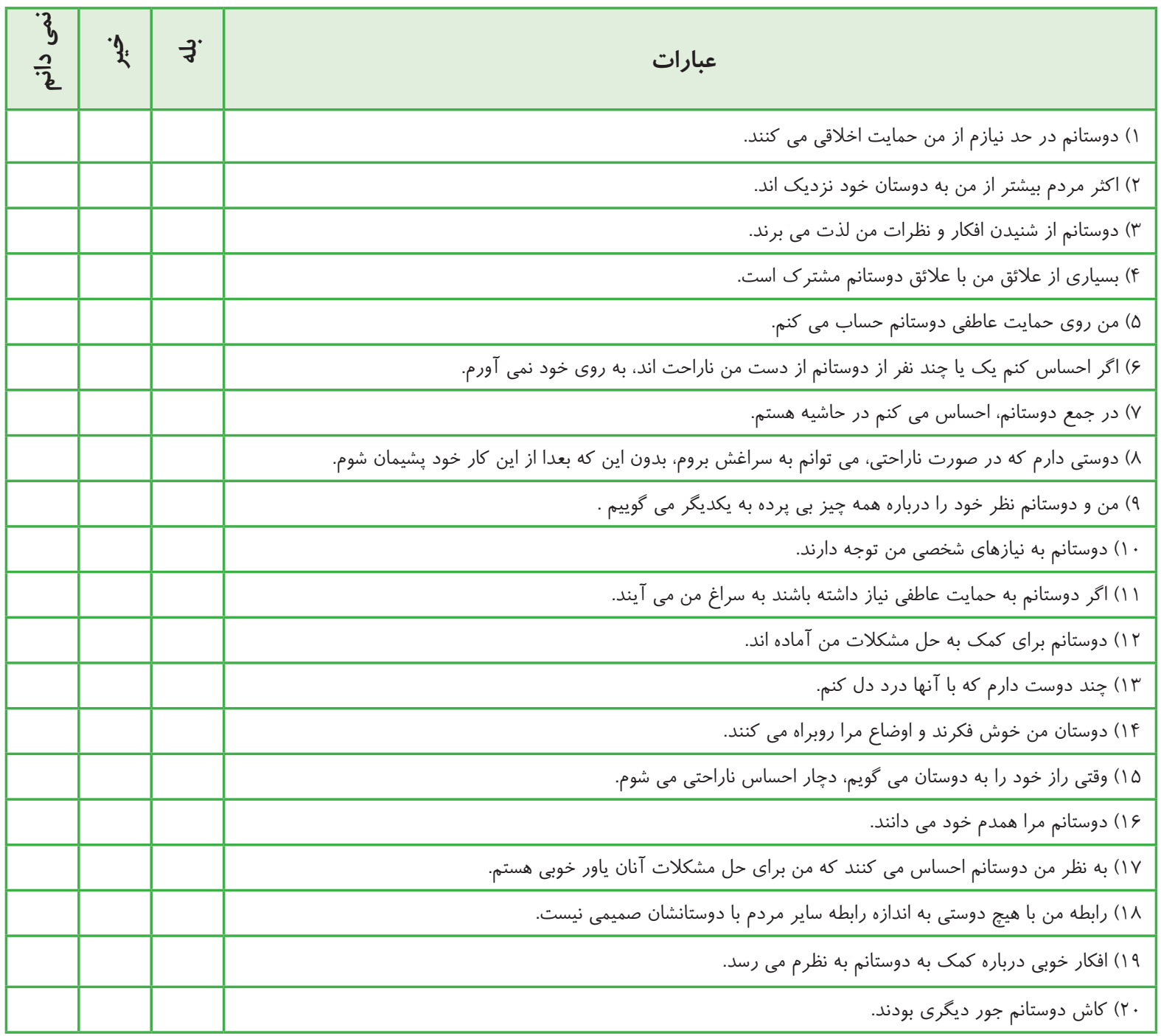

